\title{
RESPONSABILIDAD CIVIL POR ACCIDENTES DEL TRABAJO
}

\author{
Jaime Cerda Troncoso \\ Pontificia Universidad Católica de Chile \\ Universidad de Chile \\ Gerente de Asuntos Legales \\ Mutual de Seguridad C.Ch.C.
}

Trataré brevemente de compartir mi experiencia de 21 años en la Mutual de Seguridad, en materia de Accidentes del Trabajo, a razón de 200 accidentes que estudiamos mensualmente, fatales y muy graves y de una trascendencia económica empresarial increíble. También nos ocuparemos del problema de la responsabilidad civil, en cuanto al derecho a perseguir judicialmente la compensación derivada de estos infortunios laborales. Este es un tema que aún permanece oculto.

¿Por qué digo oculto? Porque hasta ahora y desde el año 1968 en que está en vigencia la Ley de Accidentes del Trabajo, se cree que por estar establecido un seguro social contra los riesgos de accidentes del trabajo, la empresa a nivel ejecutivo, a nivel medio, a nivel de supervisores, no tiene ninguna responsabilidad directa. Por tratarse de rcontingencias sociales, creen o mal creen, que esto es responsabilidad del Estado y no de las empresas. Craso error.

Yo sé que la mayoría de la audiencia está conformada por Colegas, Magistrados y alumnos de Derecho, pero si Uds. me permiten, en aras de una comprensión genérica, pues en este recinto hay personas que no son Abogados, pueda reemplazar la terminología técnica, para que mis palabras sean entendibles por todos.

Vamos a tratar de que quede bien claro el por qué hay una responsabilidad civil por accidentes del trabajo y también por qué hay una responsabilidad penal, tema este último que da para otra exposición de alguien más entendido y más versado que yo en está materia.

Para entrar en la temática tenemos primero conocer cuál es la ley que regula la materia. Esta normativa es la Ley 16.744, vigente desde el $1^{\circ}$ de Mayo de 1968.

La Ley de Accidentes del Trabajo, establece un seguro social contra los riesgos de accidentes del trabajo y enfermedades profesionales. Ya está marcando su título el contenido. Es una ley eminentemente preventiva. No es una ley curativa de accidentes del trabajo, y al hablar de una ley preventiva, tanto en su filosofía, como en su núcleo, o émbolo, insistiremos que es, ni más ni menos su objetivo la prevención de riesgos; por eso tuvo que dictarse una ley especial en el año 1968, porque a la sazón no existía para el accidentado del trabajo una protección social, una protección estatal, un seguro social, una prevención de riesgos profesionales. 
El año 1968 estaban protegidos vía seguro social los accidentes comunes y las enfermedades comunes. Una persona se accidentaba en un paseo quedaba automáticamente protegida por un seguro, por un seguro social; pero si esa persona tenía esa lesión dentro del recinto de la industria, tenía que demandar al empresario para obtener una indemnización. El empresario contrataba un seguro privado mercantil, pero no le interesaba si el trabajador era objeto de prevención. El seguro resarcía solamente el monto asegurado. Supongamos que el trabajador perdía el ojo izquierdo y no tenía visión en el derecho, no importaba a ese seguro si quedó no vidente.

Entonces esta ley, la 16.744, dijo que el asunto es distinto, aqui hay que evitar la reiteración, evitar que el accidente esté terminando con una masa laboral activa, y traspasar a una masa laboral pasiva los laborantes producto de estos siniestros.

Entrando en materia tenemos que tener en claro para que exista responsabilidad civil por accidentes del trabajo, el concepto de accidente del trabajo.

Generalmente se piensa que este accidente es el que ocurre dentro de la empresa, dentro del horario del trabajo, en los recintos, en las faenas.

Inmediatamente también les puedo preguntar: ¿Un ataque cardiaco ocurrido dentro del recinto, en horas del trabajo, es accidente laboral? Un ataque de epilepsia, dentro, en horas del trabajo ¿es accidente laboral? ¿Cuándo estamos en presencia entonces de un siniestro laboral?

El Art. $5^{2}$ de la Ley 16.744 , de ahora en adelante voy a llamarla la LEY solamente, define el accidente de trabajo como toda lesión que una persona sufra a causa o con ocasión del trabajo y que le produzca incapacidad o muerte

Son tres los elementos copulativos que deben concurrir para la existencia o configuración de un siniestro laboral. Copulativos dije, pues uno sólo que falte desdibuja el concepto y no estamos en presencia de un siniestro laboral. Los tres elementos son: la existencia de una lesión, la existencia de una relación y la existencia de un resultado. Este resultado puede ser la incapacidad o la muerte del trabajador.

Aparentemente esto es fácil. Me interesa mucho ir despejando los conceptos de antemano, para evitar preguntas que puedo contestar durante el curso de la exposición.

¿Toda lesión es susceptible de ser catalogada como siniestro laboral? ¿Se está refiriendo el legislador a lesiones físicas solamente? ¿Habrá accidente del trabajo cuando exista una lesión psíquica, a causa o con ocasión del trabajo que produzca incapacidad o muerte?

Tengo un caso de los tantos que hemos examinado donde hubo 5 accidentados, Uno con lesión física y los restantes con lesiones síquicas. Se trató de un trabajador que lo tomó una sierra en una tala de bosques, una sierra eléctrica y por la succión fue atrapado del overol y empieza a ser cercenado por la mitad. El shock que produjo a sus compañeros de trabajo fue inmenso. Uno de los cuales era su hermano, Llegaron a mi escritorio los 5 expedientes. La lesiones físicas ocasionaron a uno la muerte y otros 4 una neurosis. Todos estos siniestros se calificaron como de índole laboral.

Para denegar una calificación de Accidente laboral hay dos únicas excepciones. Tengo entendido que aquí, están presentes algunos Magistrados. Por eso, insisto, las únicas 2 excepciones - para que no exista, señores Magistrados, accidente del trabajo- 
establecidas por ley y que se pueden alegar, aunque concurran los tres elementos, son: el accidente intencional y el accidente producto de una fuerza mayor extraña al trabajo.

No estoy hablando de caso fortuito, hablo de fuerza mayor extraña, al trabajo. Aquí también hay personas que pertenecen a empresas adherentes a la Mutual que no son Abogados, por eso tienen que conocer el quehacer interno nuestro.

Fuerza mayor extraña es para estos efectos aquella producto normalmente de factores de la naturaleza y que no pueden ser previstos por la empresa al establecer un programa de prevención de riesgos. Donde termina la posibilidad científica de hacer prevención de riesgos, nace la fuerza mayor extraña.

Cuando se pueda prever anticipadamente el lugar, la hora y el día preciso en que va a ocurrir un terremoto, las víctimas del mismo dentro de una faena van a ser estar bajo la cobertura de la Ley de Accidentes del Trabajo. Por ahora, por la imposibilidad de prever científicamente la ocurrencia de un terremoto, escapa de la cobertura esa fuerza mayor extraña. Pero tiene que ser extraña, porque yo les pongo por ejemplo la caída de un rayo, que mata a un trabajador en una faena donde la ocurrencia del rayo es cotidiana. No podemos alegar ni por asomo de que eso es extraño al trabajo cuando es de una ocurrencia cotidiana y hay elementos preventivos tan antiguos como un pararrayos.

Si las fuerzas del hombre, las fuerzas humanas, ponen en movimiento a la fuerza natural, también estaremos frente a un accidente del trabajo.

Si el alud de nieve se produce porque cae la nieve del cerro y mata a los trabajadores, producto de una explosión de dinamita en las faenas mineras obviamente que el alud no se produjo por una fuerza mayor extraña. Fueron las fuerzas naturales accionadas por el hombre y, por ende, accidente va a ser calificado como laboral.

Lamentablemente en 45 minutos trataremos de dar por pasadas muchas materias, para asi avanzar en lo conceptual.

El segundo requisito que debe tener el accidente para que sea laboral, es la relación entre la lesión y el trabajo. Será directa, cuando es a causa; e indirecta, cuando es con ocasión.

Y aquí está lo más difícil, porque todos creen que el siniestro será con ocasión cuando no es a causa. O sea, si no es a causa es con ocasión. Craso error.

Les vuelvo a poner el ejemplo del ataque cardiaco. Si éste deriva de una enfermedad congénita que desarrolla su potencial dañino en horas del trabajo, no podemos enrostrarle culpabilidad a la empresa, porque ese malestar dañino va a ocurrir en cualquier parte, porque la víctima es portadora de una enfermedad común.

En otro orden de ideas, también son accidentes protegidos por la Ley, el que ocurre en el trayecto. (Accidente "IN ITINERE").

Estos siniestros acarrean problemas cotidianos para los Abogados de las Mutuales. El accidente del trayecto es el que ocurre en el recorrido directo de ida o de regreso, entre la habitación y el lugar del trabajo. La Ley sólo distrae un inciso de un artículo y un artículo de su reglamento para referirse al accidente de trayecto, y nosotros para poder establecer calificación en siniestros de trayecto, tenemos que manejar 
un sinnúmero de dictámenes propios y otros de la Superintendencia de Seguridad Social.

¿Qué se entiende por trayecto directo?: el más corto, el más breve, el geográficamente más rápido. Si decimos una salvajada, como que es el geográficamente más recto, ¿por dónde haremos atravesar un trabajador? No puede darse ningún rodeo, y atravesará ríos, montañas, todo ello porque al Abogado se le ocurrió decir que geográficamente es el más recto. ¿No habrá alguna racionalidad en el recorrido? Bueno, así va creciendo la casuística. En general, estaremos al recorrido racionalmente directo; no interrumpido por razones personales o extralaborales.

También son accidentes del trabajo, y aquí no concurre ninguna relación con el quehacer laboral, ninguna, pero lo dice la Ley: el accidente del trabajo que sufre el dirigente gremial en sus cometidos sindicales : ¿Qué vamos a distinguir ahí? Solamente, averiguaremos si la víctima es dirigente laboral y si es estaba en su cometido gremial. Pero va a ser accidente laboral solamente porque está dentro de la Ley de Accidentes del Trabajo.

Dejemos hasta ahi Colegas otra explicación. Este siniestro gremial viene de una recomendación de la OIT. Los accidentes de trayecto no tiene nada que ver con el trabajo, pero fueron explicados por el Tribunal de Casación Español, varios años antes que nosotros.

También está protegido el trabajador por las accidentes del trabajo los que ocurren en actividades de capacitación ocupacional, de ida o de regreso, o durante ellas. Su razón de ser está en el estimulo de la capacitación. De lo contrario, produciríamos un enfrentamiento entre un seguro social y algo tan elemental para evitar los siniestros laborales, como es la información y la capacitación.

Haré una pregunta. ¿Existe accidente del trabajo en un hecho donde no hay ocurrencia de lesión física ni síquica? Ud. dirán que es imposible, pues si no hay una lesión física ni síquica, o sea si no se daña la corporeidad ni la siquis, la víctima está sana y apta para el trabajo.

Les voy a dar una ayuda, especialmente y con todo respecto a los Magistrados. La Ley de Accidentes del Trabajo tiene su reglamento aprobado por el Decreto 101 del año 1968 del Ministerio del Trabajo y Previsión Social. En su art. 8 señala que es Accidente del Trabajo, la pérdida o rotura de un órgano artificial que reemplaza un órgano natural y que hace sus veces. ¿Qué pasa, entonces, con la rotura de una pierna ortopédica? ¿Vamos a dejar a ese trabajador sin cobertura porque físicamente no sufrió nada, ni síquicamente tampoco, aun cuando se le quebró su pierna ortopédica ?

Si esto no se aclara a nivel de estrado judicial, obviamente que la demanda puede inmediatamente ser rechazada de plano.

Pregunto ahora: ¿qué pasa si un trabajador que usa lentes permanentes no sufre ninguna lesión y en el accidente sólo se quebrán sus lentes? ¿Es un órgano artificial que reemplaza al natural y hace sus veces?

La respuesta es que no, porque los lentes no son órganos artificiales que reemplacen lo natural, solamente ayudan a ver, pero no hacen las veces de un ojo. ¿Cuándo la Mutual restituye los lentes? ¿Cuándo vamos a reparar los lentes? Cuando, según el Art. 29 de la Ley 16.144, exista una víctima de un accidente del trabajo. 
Es decir, si el trabajador que portaba lentes se cae de una escalera sufre una lesión en una pierna y se le rompen los lentes, restituiremos los lentes porque éstos se lo asimilan a un aparato ortopédico. Tenemos reparar estos lentes, porque la Ley de Accidentes del Trabajo otorga, gratuitamente al trabajador atenciones médicas, quirúrgicas, aparatos ortopédicos, prótesis, a las rehabilitación y reeducación profesional. Esto es así. Entonces hay que saber muy bien esto antes de recomendar demandas judiciales.

Hecho este largo preámbulo, se trata ahora de conversar sobre la existencia de responsabilidades civiles y penales, derivadas de accidentes laborales.

¿Cuándo hay responsabilidad? ¿Cuándo existe responsabilidad susceptible ser perseguida judicialmente? El Art. 69 de la Ley 16.744, señala que ello ocurrirá si el accidente se produce por culpa o dolo de la entidad empleadora o de un tercero. Vale decir, cuando el accidente laboral se produce por culpa o dolo de la entidad empleadora o de un tercero, nace todo el cuadro de responsabilidades que vamos a profundizar un momentito más, pero, repito, sólo cuando haya culpa o dolo.

\section{Si no hay culpa o dolo, no hay responsabilidad. ¿Y si el accidente es fortuito?}

Aclaremos esto. El caso fortuito en materia laboral, sobre todo en materia de accidentes del trabajo no transforma la naturaleza jurídica del siniestro como no laboral. Sigue siendo accidente de trabajo Ejemplo: si la caldera explota y se accidenta un trabajador, ¿Hay culpa?. ¿Hay dolo?, ¿Es caso fortuito?. Será caso fortuito a nivel de Derecho Civil, pero para el Derecho Laboral y en materia de Accidentes del Trabajo, la explosión de la caldera tuvo una causa producto de una negligencia, ya sea de mantenimiento, sea de vejez, del material. Siempre existe una obligación prevención. ¿Qué hizo explotar la caldera? ¿Cuándo la explosión de caldera exculparía a la empresa? Supongamos que al exterior del recinto cae un rayo y conduce electrónicamente a la caldera sus efectos. Ahí tendríamos que entrar a ver hasta qué punto esa fuerza mayor. es inherente o no al trabajo. Pero no es llegar y decir: está eximido el empleador porque el no participó, la caldera explotó sola. Nada explota por explotar en materia de accidente del trabajo, siempre hay una causa y existe gran cantidad de normas de prevención y de mantenimiento de calderas. Verán que más de alguna norma fue incumplida para que esa caldera explote, y de ser así va a existir haber una responsabilidad por de accidentes del trabajo.

El accidente por culpa del trabajador igual configura el accidente del trabajo. El accidente del trabajo sólo pierde su calidad de tal cuando es intencional o por fuerza mayor extraña. Si el trabajador actuó con culpa, podrá llegar el Juez a neutralizar o compensar las culpas. Esto es otra cosa, pero el seguro social va de todas maneras a generar indemnizaciones y pensiones de la Ley de Accidentes del Trabajo en favor de la víctima, porque sigue siendo accidente del trabajo.

¿Por qué el artículo 69 de la ley $N^{\circ} 16.744$ hace a la entidad empleadora responsable de la culpa o el dolo? ¿Por qué alude a la entidad empleadora o un tercero? ¿Quién está el obligado a hacer prevención de riesgos? ¿El Estado?. Si la ley N 16.744 crea un seguro social, ¿a qué está obligado el Estado? El Estado está obligado a organizar y fiscalizar este seguro social por los daños que irroga un infortunio laboral a un trabajador. Pero dentro de la empresa ¿de quién es la obligación de hacer prevención?

Aquí invito a todos, a los Laboralistas en especial y a los Civilistas en general, a que examinen el Art. 184 del Código del Trabajo. 
Este precepto señala: que el empleador estará obligado a tomar todas las medidas necesarias para proteger eficazmente la vida y la salud de sus trabajadores, obligando a mantener las condiciones adecuadas de higiene y seguridad en las faenas, como también otorgar gratuítamente los implementos necesarios para prevenir accidentes o enfermedades profesionales.

¿Qué les parece?. ¿A quién está dirigida la normativa? Lo dice con todas sus letras el art. 184. el empleador. Está obligación del empleador es lo que constituye en doctrina el Deber de Higiene y Seguridad. Pero no busquen, -esto va dirigido a muchos, especialmente a los alumnos aqui presentes-, no busquen las normas de prevención de riesgos en la Ley de Accidentes del Trabajo.

La Ley de Accidentes del Trabajo esquematiza un seguro social y hace obligatoria la prevención de riesgos. Pero la real normativa de prevención de riesgos está en el Código del Trabajo como norma matriz.

Este deber de Higiene y Seguridad tiene algunas características propias: no es necesario que se escriture en el Contrato de Trabajo. Es una norma de orden público, que se tiene que cumplir igual. Es una obligación contractual aunque no se exprese por escrito. Puede darse mejores beneficios a mas de esa norma vía negociación individual o vía negociación colectiva, pero por ambas vías no puede derogarse el art. 184 ni puede reemplazarse, ni puede cambiarse. Tampoco puede un empresario o empleador eximirse del deber de Higiene y Seguridad contratando un seguro privado, aduciendo que es mejor que el seguro social de la Ley 16.744.

Si quiere contratar un seguro privado contra daños personales para sus trabajadores, miel sobre hojuelas, pero igual va a seguir obligado a la Ley 16.744 .

Va a tener dos costos, porque el costo del seguro social de la Ley de Accidentes del Trabajo se financia con cargo al empleador y con dos cotizaciones, una básica y una adicional; la básica, igual el 0,95 por ciento de la remuneraciones imponibles, y la adicional que puede llegar a un 3,40 y en caso de infracciones elevarse a un 6,8 según el riesgo efectivo de la empresa. Mientras más peligroso más paga, mientras más accidentabilidad más paga. A su vez, mientras mejor de prevención, puede llegar a bajar, a descender, de tal manera que hasta puede eximirse de esa segunda cotización.

Por lo tanto, este deber de Higiene y Seguridad no queda entregado a la mera voluntad de las partes, es una norma de orden público contractual.

¿Y dónde están las normas especiales de prevención de riesgos que hay que cumplir so pena de estimar el accidente culpable y por ende perseguir judicialmente a la empresa?

Si Uds, leen el Código del Trabajo, en los Art. 179 a 183 se establece la obligación de capacitación ocupacional de cargo del empleador. Los artículos siguientes hablan de las industrias y trabajos peligrosos e insalubres, trabajos en naves y puertos, trabajos subterráneos, trabajos en tiendas y bazares, protección a la maternidad., etc.

Les pregunto: ¿El Código del Trabajo, al establecer edades límites para contratación de menores de edad, está haciendo prevención de riesgos?

¿Saben Uds, cómo puede un menor de 15 años y mayor de 14 años ingresar a una empresa con un contrato válidamente celebrado? ¿Si fuera un contrato válidamen- 
te celebrado saben Uds. que trabajos está prohibidos a los menores de 18 años? ¿Puede un hombre de 17 años laborar en faenas subterráneas? ¿Puede contratarse válidamente a un menor de 14 años de edad?

El Código está vigente hace mucho tiempo. Todos estos Artículos vienen en el Código del año 1931; es decir la prevención de riesgos no la inventaron los legisladores del año 1968.

¿La jornada de 8 horas es prevención de riesgos? ción?

¿ Es prevención de riesgos el descanso semanal o la interrupción para la cola-

¿El feriado anual es o no normativa de prevención de riesgos?

¿La protección a la maternidad es o no prevención de riesgos?

¿Todas las normas que hay sobre locomoción urbana en cuanto a los choferes y acompañantes es prevención de riesgos o no?

¿Y la normativa de los trabajadores agrícolas y los trabajadores portuarios?

¿Las normas sobre aprendices, es prevención de riesgos o no? Trabajo.

Entonces ¿dónde vamos a buscar la prevención de riesgos? En el Código del

Pero no nos debemos de quedar ahí, el incumplimiento de cualquiera norma por breve que sea del Código del Trabajo en materia prevención de riesgos, gatilla la responsabilidad civil.

Y el Código Sanitario, ¿lo conocen? ¿Establece o no condiciones que deben tener los lugares de trabajo en cuanto a ambientes, en cuanto a ecología?

¿Uds. conocen el Decreto sobre condiciones ambientales en el lugar de trabajo?

¿Saben Uds. cada cuánto tiempo debe descansar una persona que trabaja en un computador? ¿Cuánto es la jornada de una persona que trabaja al frente de un computador? ¿Cada cuántos minutos debe descansar una digitadora o digitador? La normativa está ahí, en toda esa reglamentación.

¿Conocen el reglamento de los Comités Paritarios de Higiene y Seguridad?

¿El Decreto 40 sobre prevención de riesgos profesionales?

¿El Decreto 72 sobre seguridad minera?

Estupendo si , ello es asi y además pueden recordar toda esa normativa

Pero si conocen todo eso, conozcan también el Art. 68 de la Ley de Accidentes del Trabajo, que señala que las empresas deberán implantar todas las medidas de $\mathrm{Hi}$ giene y Seguridad que directamente prescriban el Servicio de Salud o las Mutuales. Son normas obligatorias, que se suponen incumplidas al producirse un siniestro que no es intencional o que no es por fuerza mayor extraña.

¿Y qué derecho le da a la víctima el Art. 69 de la Ley? Los siguientes: cuando el accidente o enfermedad se deba a culpa o dolo de la entidad empleadora de un tercero, sin perjuicio de la sanciones criminales que procedan regirán o las siguientes normas. 
Pero dejemos ahí el recuerdo del texto. La responsabilidad penal existe entonces. Desde ya les digo que son alrededor de 61 días a 3 años de cárcel la sanción derivada de responsabilidad penal en un accidente laboral. ¿y cuándo hay responsabilidad penal?

No voy a hacer reflexiones sobre lo que entendemos por delito o cuasi delito penal. Lo único que quiero recordar son las dos consecuencias de un accidente de trabajo en cuanto a resultado: lesión o muerte.

¿Existe el delito de lesión penado por la ley?. Existe. $Y$ si hay culpa y no dolo ¿habrá un cuasi delito de lesiones? Si. Y por la muerte de un trabajador ¿existe o no el delito de homicidio?, ¿existe o no el cuasi delito de homicidio? Entonces, reconocida sigamos con la responsabilidad civil.

Continúa el artículo 69 de la ley, agregando que deberán observarse las siguientes reglas: $1^{2}$ La Mutual tendrá derecho a repetir contra el responsable del accidente por las prestaciones que haya otorgado o deba otorgar.

¿Qué significa esto? Que frente a un accidente doloso o culpable la Mutual puede accionar contra ese culpable y recuperar desde un parche curita hasta las pensiones vitalicias que tenga que pagar por ese accidente culposo. Eso es facultativo para la Mutual. Si quiere lo ejecuta. Pero vamos al accidentado, a la víctima del infortunio o a su sucesión.

La víctima y las demás personas a quienes el accidente o enfermedad cause daño, podrán reclamar al empleador y terceros responsables del accidente las otras indemnizaciones que tengan derecho con arreglo a las prescripciones del derecho común, incluso el daño moral.

Fijense bien, existirá responsabilidad civil porque se causó daño por un accidente culposo, porque se incumplió con la responsabilidad contractual laboral que emana del Código del Trabajo, esto es por incumplimiento del Deber de Higiene y Seguridad.

Hay grandes tendencias sobre la procedencia del daño moral, en la responsabilidad contractual.

Sin embargo, la Ley de Accidentes del Trabajo no entra siquiera a distinguir, ni a discurrir nada. Expresamente el artículo 69 señala que también existe responsabilidad por el daño moral. Lo dice expresamente.

Entonces qué fácil va a ser para la víctima de un accidente del trabajo accionar por responsabilidad civil.

¿De quién es el peso de la prueba? Antes de contestar esta pregunta veremos primero a que tipo juicio nos enfrentamos.

Como el Art. 69 dice: Las indemnizaciones que tengan arreglo de acuerdo con las prescripciones del derecho común. Aparentamente, por tratarse responsabilidad civil se entiende que se trataría de un juicio civil.

Eso era posible de discurrir o de discutir hasta antes de la entrada en vigencia de la ley 19.447. Esta, al modificar el Art. 420 del Código del Trabajo y agregarle la letra f) entrega a los Juzgados del Trabajo la competencia en todo lo que se refiera a accidentes laborales por responsabilidad contractual, quedando para los tribunales civiles y del crimen la responsabilidad extracontractual. Pero como el accidente del trabajo 
emana de un incumplimiento de una obligación en cuanto a protección laboral contractual el trabajador acudirá al Juzgado del Trabajo.

Esto tiene mucha importancia en cuanto al peso de la prueba, en cuanto a la prescripción, en cuanto a los perjuicios. Pero, lo más importante es en cuanto a la prueba.

¿Qué debe hacer en el Juzgado del Trabajo el laborante? Llevar su contrato de trabajo, pues necesita acreditar que es trabajador de la empresa. Es decir, entrega el contrato de trabajo, y después la resolución de la Mutual que calificó el siniestro como accidente del trabajo. El Juez al constatar que hay accidente del trabajo y cerciorarse que se trate de un trabajador dependiente de la empresa deben, examinar, la defensa de la empresa. La empresa solamente puede defenderse alegnado que no tiene culpa y que ésta es de cargo del trabajador. O sea, el empresario tiene que demostrar que la culpa la tuvo el trabajador, y que en su calidad empleador fue óptimo y eficaz en su cumplimiento de las normas de prevención.

¿Qué debería preguntar el Magistrado para responder a esa eficacia de la empresa? 1․- Ud. tiene una obligación de Higiene y Seguridad ¿la cumplió? ¿Cómo la cumplió? Otra pregunta del Juez: ¿Cuántos trabajadores laboran en su empresa? Supongamos una empresa más más de 100 trabajadores, es preciso preguntar, ¿tiene Comité Paritario de Higiene y Seguridad? El Comité Paritario de Higiene y Seguridad está reglamentado en el Decreto 54 y es una obligación legal. Se compone de 3 personas designadas por la empresa y 3 elegidas por los trabajadores. Son los únicos competentes para determinar si el accidente ocurrió negligencia inexcusable. Si la empresa no tiene constituido el Comité Paritario de Higiene y Seguridad, inmediatamente esa entidad empleadora va a estar demostrando que no capacitó o mal capacitó a sus trabajadores.

Supongamos que tiene cumplida la obligación de contar con el Comité Paritario. Otra pregunta debería ser ¿Tiene Reglamento Interno de Orden, Higiene y Seguridad? El Art. 153 del Código del Trabajo, obliga a toda empresa industrial o comercial de más 25 trabajadores tener un Reglamento de Orden, Higiene y Seguridad, donde se indique al trabajador todas las obligaciones derechos y deberes en materia de prevención de riesgos.

Alguna empresa puede alegar, como lo ha hecho en ciertos juicios, que tiene 23 trabajadores y por lo tanto no está obligada a tener Comité Paritario, ni tampoco Reglamento Interno. Preguntamos: ¿Cumplió con el Decreto 40 y el Art. 67 de la Ley 16.744? Ambas normas obligan a toda empresa a tener un reglamento de Higiene y Seguridad en el trabajo aunque tenga un solo trabajador contratado. Por ende, si no está obligada al Reglamento Interno del Código del Trabajo, quedará obligada al Reglamento Interno del Art. 67 de la Ley 16.744.

Otra pregunta que debería hacer el Juez es la siguiente si tiene 150 trabajadores ¿Existe un Departamento de Prevención de Riesgos dirigido por un experto en prevención de riesgos?: Si la respuesta es negativa, debería acoger de inmediato la demanda del trabajador.

Supongamos que la empresa tiene Departamento de Prevención de Riesgos. La pregunta del Juez tiene que ser: ¿Ud. cumplió con el Decreto 40, con la obligación de informar los riesgos laborales? Es obligación de la empresa informar los riesgos labora- 
les, sea, a través del Comité Paritario, en un anexo del contrato de trabajo o como estime pertinente, pero debe hacerlo forma pedagógica.

Colegas, cualquiera de las anteriores preguntas que se conteste con un NO, la defensa termina ahí. En Derecho Laboral y en los Juzgados Laborales, debe terminar ahí. No hubo prevención, no se cumplió con la obligación contractual de higiene y seguridad contenida en el artículo 184 del Código del Trabajo.

Aceptamos que la empresa tiene capacitados a sus trabajadores y debidamente informados de los riesgos. ¿Qué debiera hacer el tribunal? Creemos que corresponde efectuar Inspección ocular del Tribunal. Por ejemplo: Si la víctima cayó del vigésimo piso, de un andamio, por sufrir un ataque de epilepsia. La pregunta del Juez sería o deberiera ser. Se hizo un examen pre ocupacional al trabajador, antes de enviarlo a trabajar en altura? Si la respuesta es no, la defensa nada tiene que hacer. También termina el juicio ahi. Porque el empleador tiene que administrar la empresa como un buen padre de familia y allí hubo una negligencia.

Me imagino que don Pedro Zelaya les habrá explicado, con la sapiencia que tiene, sobre las responsabilidades vicarias: toda la suerte de culpas que terminan por inculpar a una empresa por un hecho de su dependiente.

Veamos ahora, en qué se traduce la responsabilidad civil: En resarcir el daño, ¿Qué daño? El daño material, el daño moral. Uds. deben saber que ya pasó de moda definir el daño moral como el pretium doloris. Este, es una parte del daño moral. Hoy día el daño moral es mucho más que el pretium doloris.

¿Cómo se indemnizará el daño moral? Distinta será la indemnización por un trabajador que agonizó un año, como la de un trabajador que murió instantáneamente. ¿Qué debe contener la sentencia en estas materias?: Una evaluación detallada del daño moral. Pero todavía no se atreven los tribunales, con el debido respeto a los Magistrados, a explicitar el daño moral en las sentencias.

Engloban el daño moral sin discurrir. Se preocupan más del lucro cesante. ¿Y cómo lo hacen?: Por ejemplo, un trabajador de 21 años. ¿A qué edad jubilan los varones? ¿Cuánto ganaba? ¿Cuánto recibe la viuda por la pensión de la Mutual? ¿Cuánto dejó de percibir? Ahí saldrá una indemnización por lucro cesante intersante con el agregado del daño moral.

También es justo destacar que en un Juzgado de Talcahuano se estimó que la culpa del accidente fue del trabajador, pues él se negó a usar los elementos de protección. Se le entregaron elementos de protección, firmó la recepción; también fue objeto de capacitación. La empresa fue absuelta de todo pago por indemnización civil, pues la culpa fue del trabajador, ya que se expuso al riesgo en forma imprudente.

Creo yo que ese juicio lo ganó la empresa porque la familia del trabajador golpeó una puerta que no corresponde. Se fue a un Juzgado Civil y trasladaron el peso de la prueba para un lado que no correspondía. Si se hubiera ido a un Juzgado Laboral estaría comentando otra cosa.

Pero lo más decidor fue un caso donde por no contestar ciertas preguntas, y otras que les voy a decir, no se condenó al empleador sino que se condenó al mandante. Esta empresa mandante celebró un contrato con un contratista y el accidentado fue el laborante del contratista. ¿Y qué dice el Art. 64 del Código del Trabajo?: El mandante 
es responsable subsidiariamente de las obligaciones laborales y previsionales de los contratistas y de los sub contratistas.

Es la responsabilidad que la doctrina llama en cascada, pues la víctima demanda a su empleador directo y notifica la demanda también al mandante.

Bueno, se condenó en este caso al mandante a la suma de 463 millones de pesos y al contratista persona natural a 2 años de presidio, porque el juicio se inició por cuasi delito de homicidio en el Juzgado del Crimen. La demanda civil se interpuso en el plenario.

Es decir, la responsabilidad civil es en el accidente del trabajo tan fácil, de perseguir, pues basta el incumplimiento de una pequeña norma de prevención.

¿Qué exige la responsabilidad civil? Primero que exista un daño, el accidente produce lesión o muerte, o sea daño; luego que haya imputabilidad, obviamente que uno no va a demandar no a un niño ni a un demente, va a demandar a un representante legal, a un empresario que supone capaz. ¿Qué pasa con la responsabilidad de las personas jurídicas? La persona jurídica igual va a tener que pagar. Pero ¿y la responsabilidad penal? ¿Qué pasa con las corporaciones, con las sociedades? ¿Quién responde penalmente como el contratista? Con las personas naturales no hay problemas, pero con las personas jurídicas ¿Qué pasa con la responsabilidad penal?

El Art. $4^{\circ}$ del Código del Trabajo establece una presunción de derecho.

El Art. 39 del Código de Procedimiento Penal inculpa al que hubiere intervenido en el hecho. Nadie puede eximirse diciendo que no intervinó directamente. ¿Cuántas sentencias tenemos de autores que intelectualmente participaron en él?

Quiero dejar sentado que la Prevención de Riesgos es seria, muy antigua, no del año 1968. Tan antigua que me voy a ir en un viaje largo, porque tengo el historial retroactivo para ir indicando como el Art. 184 copió al 171, el 171 al Art. 86 del D.L. No 2.200, el 86 ¿a cuál copió? al 244 de Código del Trabajo del año 1931. ¿Hasta donde llegamos?

Yo me voy a quedar en el Libro del Deuteronomio, ¿Qué dijo nuestro Gran Hacedor a Moisés?: "Cuando vayas a construir un edificio, circunda la terraza con un parapeto, para que no deje de ser sagrada debido a la sangre del trabajador que de esa terraza pueda caer". Esto dijo le Ley Mosaica.

¿Qué nos dice el Nuevo Testamento?: Ama al prójimo como a ti mismo. El trabajador es un prójimo. Nosotros ipor qué tenemos en nuestra casa cuidado y protegemos a nuestros hijos, a nuestra familia, exógena y endógenamente?, ¿Por qué no hacer lo mismo en una empresa? ¿Qué va a pasar con la empresa si es culpable de un accidente por fallar en su prevención, y se muere un trabajador?

En la Ley Mosaica esa empresa dejaba de ser sagrada. En el Nuevo Testamento pierde la gracia santificante.

En la medida que se haga alternativos los conceptos productividad y seguridad, habrá drama, habrá siniestralidad; pero en la medida en que se los trate como bienes complementarios, existirá protección y vida. 
Se trata de tener presente que hay una vida, que hay una obligación de Higiene y Seguridad, que hay un trabajador que proteger.

Creíamos que la prevención de riesgos estaba solucionada por la vía administrativa de la Ley 16.744 , creíamos que por la vía del incentivo de la rebaja de cotización adicional estaba asegurada, que se había involucrado la empresa en evitar los accidentes laborales; mas, la real prevención se está haciendo a nivel de Tribunales de Justicia, paralelamente al seguro social.

Esto está creciendo, y esta Ley que se enorgulleció en su época y se enorgullece actualmente de ser un paradigma de protección, está siendo tratada en los Tribunales, por el aumento del incumplimiento de las normas de prevención de riesgos profesionales. 